\title{
Come Hell or High Water: Doctoral Students' Perceptions on Support Services and Persistence
}

\author{
Melanie Greene \\ Memorial University of Newfoundland, St. John's, NL, Canada \\ melaniejg@mun.ca
}

\begin{abstract}
While a lack of support has been identified as a contributing factor to non-persistence in graduate studies, there is an absence of literature that matches the provision of specific types of support services with outcomes at the doctoral level. The following questions were addressed in this study: (1) What is the role of institutional support in the persistence and success of graduate students? (2) What do students feel are some of the biggest barriers to graduate student persistence? (3) What do students feel are some of the factors that have a positive influence on persistence? Qualitative methods were employed; eleven interviews were conducted with current and former students who were currently or had previously been enrolled in a doctoral degree program in the social sciences and humanities disciplines. The study was undertaken at a large comprehensive university in Atlantic Canada.

Overall findings point to the need to make transparent to doctoral students the role of institutional units and the support services they provide and the need to promote and raise awareness of these services. Five key themes emerged from this study with regards to doctoral student persistence and the role of support services: (1) the unclear role of institutional support; (2) financial considerations; (3) the culture and structure of academia; (4) individual characteristics; (5) support of others. Recommendations for policy, practice, and further research are presented.
\end{abstract}

Keywords: doctoral students, student development, persistence, student services

\section{Introduction}

Despite the recognized importance of a graduate degree to those wishing to compete in today's knowledge economy, graduate students frequently do not complete their programs and leave at levels that often exceed graduation rates. Fewer than half of those who start a doctoral program in the arts and humanities and social sciences disciplines actually graduate, and these faculties have the lowest completion rates at both the master's and doctoral degree levels (Elgar, 2003). Doctoral students in these fields of study are also reported to have the longest times to completion, with

Material published as part of this publication, either on-line or in print, is copyrighted by the Informing Science Institute. Permission to make digital or paper copy of part or all of these works for personal or classroom use is granted without fee provided that the copies are not made or distributed for profit or commercial advantage AND that copies 1) bear this notice in full and 2) give the full citation on the first page. It is permissible to abstract these works so long as credit is given. To copy in all other cases or to republish or to post on a server or to redistribute to lists requires specific permission and payment of a fee. Contact Publisher@InformingScience.org to request redistribution permission. averages hovering around 77 months (Canadian Association of University Teachers, 2011). Yet, enrolments in graduate programs continue to increase. In the first decade of the twenty-first century, enrolments in master's degree programs in Canada rose by $43 \%$, while enrolments at the doctoral level rose by $70 \%$ (Canadian Association for Graduate Studies, 2012). 
While the quality of the graduate experience and student success is variable, effective academic and social support services are believed to play an important role (Polson, 2003). The integration of doctoral students into the university community and the academic culture has important implications for their persistence, success, and degree completion (Tinto, 1993), and attrition has economic, social, and personal ramifications for students and institutions (Lovitts, 2001).

Much of the research that has been conducted on graduate education to date has focused almost exclusively at the doctoral level in American institutions. Concerns with issues such as the high rate of student attrition and the lengthy time it takes to graduate have led to a number of government supported initiatives (Walker, Golde, Jones, Bueschel \& Hutchings, 2008; Zhao, Golde \& McCormick, 2007). Several studies have also examined the role of demographics, student involvement, and other factors in student socialization (Gardner \& Barnes, 2007; Lovitts, 2001). More recently, attention has been drawn to student development and the benefits of increased programmatic support (Gardner, 2009b; Sweitzer, 2009). While extensive research has been conducted on graduate education, inquiry into the role of support services on student experiences is sparse.

\section{Literature Review}

Undergraduate student attrition research theorizes that persistence is the product of a complex set of interactions among personal and institutional factors (Bean, 1980; Cabrera, Castaneda, Nora, \& Hengstler, 1992; Tinto, 1975). A theoretical 'Graduate Student Transition Model' was recently developed based on an amalgamation of pre-existing models of student persistence and attrition and considers the current literature on graduate student characteristics and experiences (Greene, 2013). This model stands as a preliminary exploration into the graduate student experience and gives considerable attention to the factors thought to play a role in students' decisions to enroll and persist in graduate school. Specifically, it posits that the student experience, and the persistence decision-making process, is influenced by such factors as goal commitments, the job search, student development, internal and external factors, and psychological outcomes.

Increased levels of student involvement have been found to be influential in persistence at the undergraduate level (Astin, 1984) and play a key role in graduate student socialization and professional development (Gardner \& Barnes, 2007). Academic and social integration have been addressed in the context of student attrition and persistence at the graduate level by several researchers (Ethington \& Smart, 1986; Mullen, Goyette, \& Soares, 2003; Tinto, 1993). Academic integration includes a student's level of formal and informal involvement in the institution; social integration refers to the extent of a student's involvement in relationships with peers and faculty (Mullen et al., 2003). External influences, such as family and work, can also affect students' integration into their program or institution and may be influential in persistence decisions (Sweitzer, 2009).

There has been extensive discussion around the phases of graduate school socialization, which Golde (1998) describes as the process in which a graduate student is made a member of an academic department in a particular discipline. Tinto's (1993) seminal work on undergraduate persistence implies that persistence is a result of successful socialization. An insufficient level of socialization may thus result in attrition. The socialization of graduate students has been framed within theories of student development, and several developmental phases are shown to characterize the doctoral student experience (Gardner, 2005; Lovitts, 2001; Tinto, 1993; Weidman, Twale, \& Stein, 2001). Much of the research on the graduate student socialization experience to date has taken a theoretical approach and has not given consideration to specific contexts and disciplinary differences. More recently, the academic culture has been explored in relation to persistence and retention (Bieber \& Worley, 2006; Golde, 2005; Gardner, 2005; 2009a; 2010). 
Student attributes and program characteristics (Franco-Zamudio, 2009; Gittings, 2010), as well as both institutional and non-institutionally-based support (Boulder, 2010; Williams-Tolliver, 2010) has been shown to play a role in graduate student persistence and degree completion. Key to these analyses is the role of student perceptions in determining the effect of such factors on persistence.

Limited research to date has focused on specific support services for graduate students, such as professional-development (Holaday, Weaver, \& Nilson, 2007), counselling services (Oswalt \& Riddock, 2007), thesis writing support (Elgar, 1998), housing (Mills, 2006), orientation (Polson, 2003), funding (Strayhorn, 2010), and pan- university institutional initiatives (Bair, Haworth, \& Sandfort, 2004).

Attention has been directed to efforts to foster a sense of community on university campuses and the need to create graduate student specific gathering places and spaces where services can be accessed and support networks established (White \& Nonnamaker, 2008). It is thought that such efforts give students a sense of being valued by the institution (Brandes, 2006). Research has also examined the role of peers and social networking in graduate student development and persistence (Hildebrandt, 2011; Sweitzer, 2009).

While it is evident that a lack of adequate support is an important factor in attrition (Lovitts, 2001), there is a dearth of literature dedicated to the assessment of support services and programs (Boulder, 2010; Holaday et al., 2007; Poock, 2004). Specifically, there is a lack of research that matches the provision of specific types of support with any type of outcome at the doctoral level.

To address this gap in the literature, this research sets out to explore the types of support services available to assist doctoral students and to determine what effects, if any, they have on persistence. The following questions were addressed in this study: (1) What is the role of institutional support in the persistence and success of graduate students? (2) What do students feel are some of the biggest barriers to graduate student persistence? (3) What do students feel are some of the factors that have a positive influence on persistence?

\section{Purpose of the Study}

The purpose of this study is to explore the support services available to assist doctoral students and to determine what effects, if any, they have on persistence. While the importance of social and academic integration to student retention has been acknowledged in the literature, very little research has explored the role of specific support services in students' decision to stay or to leave. This research makes a significant, original contribution to the existing literature on doctoral student persistence and the role of student support services, while situated in the context of Canadian graduate education.

The theoretical framework guiding this study is student development, premised on the importance of the main components of challenge and support. According to Sanford (1966), development occurs as the result of two conditions: challenge and support. When students face a challenging new experience, they are prompted to respond. If they do not receive the support needed to overcome these challenges, however, development may be hindered (Gardner, 2009b). A balance must thus be maintained between these two components if development and growth is to occur. Within this context, a myriad of experiences and transitions are essential components of the developmental process. Particularly relevant to graduate student development processes is socialization and the role of student support services. Student development theories have proved useful to help make sense of undergraduate student attrition and retention (Pascarella \& Terenzini, 2005; Strange, 2010); graduate students have, until recently, been left out of this important dialogue. While several models of student development were influential in framing this study, no one specific approach formed the framework; the process of how development occurs was used to characterize an understanding of the doctoral student experience. This research is concerned with how 
the balance between challenge and support is attained and maintained, how this process abets or hinders persistence, and the outcomes of that struggle, as told from students' perspectives.

It should be pointed out that a distinction is made here between the terms 'persistence' and 'retention'. While the former refers to a "way of thinking about student progress which asks whether the student continues in higher education", and ultimately offers a student view, retention offers an institutional perspective, asking whether students are progressing through the institution in which they are enrolled (Tinto, 2012). This study is primarily interested in the factors that influence graduate student persistence, with an emphasis on the role of support services and programs, thus focusing on the students' perspectives but not restricting its analysis to any one particular institution. Meanwhile, this research is situated in a single institution; so, while students were encouraged to share their experiences in other graduate programs at other universities, and many did so, the persistence of graduate students enrolled at the university under study is the focus.

\section{Research Methodology}

This paper discusses the qualitative findings from a larger study (Greene, 2014) that utilized a mixed methods approach, a mixing of both quantitative and qualitative data (Creswell \& Plano Clark, 2011). Qualitative research has been described as "... an effort to highlight the meanings people make and the actions they take, and to offer interpretations for how and why" (Luttrell, 2010, pp.1-2). Qualitative research is thought to be particularly relevant to the study of doctoral education, where the student role is characterized by a lack of agency (Gardner, 2005). By describing experiences through the voices of students themselves, the researcher may gain understanding and insight. The study captures data from students who completed their program as well as those who did not finish - those who withdrew or were dismissed.

\section{Data Collection}

Methods of data collection in this study consisted of an online survey, interviews, document analysis, and informal observation. This paper focuses solely on the qualitative portion of the study and, more specifically, the interview portion of data collection. Interviewing was chosen as a means of data collection as this approach allowed for an opportunity to better understand the experiences of graduate students. Seidman (2006) notes that the purpose of in-depth interviewing is to gain an understanding of the lived experiences of other people and the meaning they make of that experience. Pilot interviews were first conducted with two graduate students for the purposes of testing the interview protocol, with the possibility of revising and editing questions for clarification. Following the pilot, students were recruited from phase one of the larger study, which consisted of an online survey, to participate in a follow-up interview - the purpose of which was to explore more fully the reasons students choose to persist or not and how their experiences may relate to institutional-based support.

A total of twenty interviews were conducted; eleven of these were with doctoral students - the focus of this discussion. Interviews were loosely structured around a script of 16 questions, with the use of several follow-up questions or prompts where necessary. Interviews lasted approximately one hour in duration and were recorded for the purpose of analysis through the use of a digital audio recorder and were transcribed verbatim. While the preferred method was face-toface, those who wished to participate but were unable to participate in person were interviewed via telephone or through the use of telephony applications (i.e., Skype). A total of five interviews were conducted face-to-face; two interviews were conducted via Skype; three were interviewed over the telephone; one participant responded to the questions via email. 


\section{Research Setting and Participants}

This study was conducted at a large, publically-funded comprehensive university in Atlantic Canada. The institution was chosen due to its proximity and access to the researcher, as well as its somewhat unique organization of the social science and humanities disciplines into a Faculty of Arts. It was believed that this categorization would enable easier recruitment of participants, due to having a central 'home' unit from which to draw, and would also aid in the analysis with regards to disciplinary context and departmental structure.

Initial contact was made with representatives within the Faculty of Arts, such as department chairs/heads, administrative staff, and graduate program coordinators, to explain the details of the study and for the purposes of gaining an understanding of the program structures and supports for graduate students in each department. Participants were drawn from a study population of all current and former graduate students at the institution under study, who were or had been enrolled in a masters or doctoral program in a social science or humanities discipline in the last seven years. As per the university requirements, seven years is the maximum amount of time that is given for students to complete a graduate program without incurring continuance fees and, in some cases, being required to obtain special permission to continue.

Interviewees were initially recruited from a random sample of those who completed an online survey and indicated an interest in participating. Random sampling is a method of selecting participants in which every member of the target group has an equal chance or probability of being selected to participate, ensuring that the sample will be representative of the population (Creswell, 2009). Of 150 initial survey respondents, a total of 45 students indicated an interest in being interviewed; from this target group, a random sampling procedure was conducted using the Statistical Package for the Social Sciences (SPSS 19). The sample represented one-third of the pool of potential interviewees and was determined to be a sufficient number based on time and resource constraints as well as the possibility of saturation.

Students who were randomly selected were contacted via email and asked if they were still interested in participating in an interview. A letter of information and consent form were attached to the email for their review. As a sufficient number of participants was not initially attained, a second random sample was conducted and efforts made through email and posters, and later through snowball sampling, to recruit further participants. While every attempt was made to maintain an equal balance of gender and age, as well as proportion by program, due to the voluntary nature of participation, this was not always possible.

At the time of the interview, five participants were currently enrolled in a doctoral program. Four participants had graduated from a doctoral program and were no longer enrolled as students. Two participants were not currently enrolled and did not complete their most recent doctoral program at the institution under study. One of these participants chose to withdraw from their program; the other was terminated (academically dismissed).

Of those five participants who were currently enrolled at the time the interviews were conducted, one student was beginning year two of the program, two were in year three, and two were in year four. All were enrolled full time. Of those participants who graduated from their doctoral program, the average time to completion varied widely. One student took only two and a half years to complete; the three others exceeded the expected four or five years for completion. One student took six years; the other two took seven years, one of which took a paid leave (externally funded). Of the two participants who did not finish their doctoral program at the institution under study, one left in year three (after successful completion of the comprehensive exams), and one left after year seven (after completion of fieldwork). 


\section{Data Analysis}

Transcribed interview data was analyzed following a grounded theory approach, which seeks to generate a theory based on the categorization and coding of the data that emerges (Glaser \& Strauss, 1967). A series of steps are followed known as constant comparison, "a research design for multi-data sources, which is like analytic induction in that the formal analysis begins early in the study and is nearly completed by the end of data collection" (Bogdan \& Biklen, 2003, p. 66). This process allowed for the identification of the salient themes that emerged from participant's interview responses. Analysis through the constant comparative method resulted in a coding system, which was then compiled into a larger set of themes. Descriptive data in the form of textinterview transcripts and the researcher's field notes was organized through the process of coding, according to concepts and categories that emerged.

Peer debriefing, a technique whereby the researcher shares findings and elements of the research with peers or colleagues, was employed. This allows the researcher to think critically about the research, test hypotheses, and to acknowledge any feelings that may affect judgment. A graduate student peer was available to read over transcripts and conducted an independent assessment of the interview data to verify that the themes and constructs embedded within the data aligned with those of the researcher. Member checking, the process of engaging participants in data analysis for verification was also performed. Participants were given copies of their interview transcript, as well the researcher's own written analysis. They were provided with the opportunity to verify the study's findings and offer any suggested changes to be made.

While participants were asked a range of questions relating to their experiences as doctoral students, this paper focuses on responses to questions that pertained directly to the three research questions that guided the study. The findings shared here are an amalgamation of participant's responses to the following interview questions:

- Have you ever considered leaving/not completing your graduate program? (If yes, please talk a bit about this experience; if no, please explain).

- What are some of the factors that influenced your decision to persist/leave your graduate program at Memorial?

- What is the most important factor that influenced your decision to persist/leave your graduate program at Memorial?

- In your experience/opinion, what are some of the biggest barriers to graduate student persistence?

- What do you believe/think is the role of support services in graduate student persistence and success?

- Could you please identify what you consider to be the most important services and programs provided for graduate students at Memorial?

- What types of support services and programs would you like to see offered specifically for graduate students at Memorial?

\section{Findings}

While the experiences of participants were quite varied and context-specific - depending on such factors as the discipline and/or department of study, the structure and organization of the doctoral program, and the phase of study - several predominant themes emerged from interview accounts with regards to doctoral student persistence and the role of support services: (1) the unclear role 
of institutional support, (2) financial considerations, (3) the culture and structure of academia, (4) individual characteristics, and (5) support of others.

\section{The Unclear Role of Institutional Support}

When asked to identify what they felt is the role of support services in graduate student persistence and success, participants indicated that they were generally not very familiar with programs and services offered by the various academic and administrative units at their university, nor were they very clear on what the role of each of these specific divisions is. Current and former students were least knowledgeable about programs and services offered through the Faculty of Arts and the university's school of graduate studies. Thus, the role of these units in graduate student success and persistence was unclear to them. Typical of such responses is the following:

The university is a big place, with all these different groups and departments. I didn't really fully understand who did what...I didn't really have much contact with any of them.

The most dominant theme that arose from these discussions was the apparent disconnect between the availability of services and the level of outreach being done to promote awareness of these services. In the words of one student:

Sometimes it turns into white noise. There might be great services available, but if they're not communicated to us in some way that is clear, then it doesn't matter whether they're there.

Others claimed to have never felt a need to utilize the services available to assist graduate students.

I never had recourse to them... I didn't feel a need, and maybe that reflects that I was very comfortable in what I was doing and I had a vision of where I wanted to go.

Comments made by several participants reflected a noticeable gap in the services offered, especially in terms of providing students with a sense of support and belonging as a member of the graduate student population and the wider university community.

I think that's really important to create a community of students and a culture of support for each other.

Participants most frequently cited the following supports when commenting on their role in student persistence: health services, professional development and academic supports, and funding and supervisory support. A number of participants also emphasized the role of the department as a supportive unit in terms of providing programs and services.

... in terms of graduate student support I think it's at the departmental level that you get the most as a graduate student.

\section{Financial Considerations}

Funding was seen as both an incentive and a barrier to graduate student progress and time to completion. While those participants who received funding often cited financial support as having a positive influence on their persistence, those participants who received little to no financial support frequently cited financial hardship as a barrier to persistence. Comments underscored the importance of considering financial matters as an essential component of the graduate student experience, and as a determining factor in persistence.

[Funding]...it's such a big issue. It's so stressful and there's no funding. Having the money and having the time is like central to all of this. I know I'm supposed to say it's all be- 
cause you love what you do but if you don't have the means to actually focus on it, then it doesn't really matter.

Financial support was the third most frequently cited factor considered to be most important to interview participants' own persistence, behind a high level of support and a personal commitment to finish. In all but one of these cases, the participant had received a significant amount of external funding. Participants mentioned financial support most often when they were asked to identify the following: (1) what universities can do for graduate students; (2) the most important services and programs for graduate students at the institution under study; (3) types of support services and programs they would like to see offered specifically for graduate students at their institution.

Many participants made reference to the struggle of balancing coursework and research with work-related responsibilities. As a graduate in this study recalled:

There was an almost complete lack of financial support... Working almost full time extends our program and increases our stress levels beyond a bearable level. This creates a situation in which it is almost impossible to learn, and it removes the joy from any learning that does take place.

Similarly, a current student recalled having encountered financial difficulties "right from the outset." This student, who moved from another province, was offered a funding package which "didn't materialize in the first semester", leading to frustration with the program and financial hardship in the first semester.

Financial barriers can have a significant effect on persistence and participants noted that these are not often considered in institutional reflections on the causes of attrition. Participants indicated that they would like to see universities take more responsibility in providing financial support to graduate students, and that financial matters be taken more seriously. These concerns are exemplified by the following comment from a former doctoral student:

I think there is an avoidance of acknowledging the financial struggles of students. They don't want to hear if you're having financial problems. They think that's not their problem, and I think that needs to change.

\section{Culture and Structure of Academia}

The culture and structure of academia came up as a significant barrier to doctoral student persistence, with participants noting the systemic nature of attrition and lengthy times to completion. The culture of the institution and a lack of 'perceived' support was also seen as an impediment to progress. This lack of perceived support may be at least partially responsible for some participants' perceptions of a poor fit between their own expectations and those of the department, the institution, doctoral studies, or graduate school in general. Again, this points to the importance of promoting and raising awareness of services available and enhancing what services students' feel to be most important, as well as addressing any significant gaps.

Participants in this study also mentioned the management structure of the institution as being responsible for the demands being placed on faculty to gain students and boost graduate student enrolment. Many students spoke of what can be described as a 'suck it up' mentality they saw from supervisors and faculty members, which they felt was unsupportive, and symptomatic of the culture of academia itself.

There's this heroic narrative that goes with graduate students that you must overcome these obstacles, just as supervisor X or Y did. And that if you don't struggle in the same 
sort of way they did, or in the way they remember having struggled, that it's not [an] authentic graduate student experience...

Often, participants resorted to 'other-worldly' analogies when talking about the structure of academia, what one student termed "a feudal system" of dominance. Another former student compared academia to a mythic tale of violence:

This priest has a temple, near a pond in the middle of the forest. And the way you get to be the priest is to kill the incumbent priest and to survive the attacks of all the other priests. That's a lot like academia isn't it, really?

A number of participants expressed a sense of disenchantment with the academic profession. A student who ultimately ended up being academically dismissed from his program recalled having experienced difficulties at the writing stage. He did not receive timely feedback from the supervisor, which slowed the process and resulted in feelings of incompetence and bitterness. Another student who withdrew from her program felt that opportunities for the practical application of academic research were too limited and the publication process very elitist in its capacity to reach out to those beyond academia:

You work and you work and you work to publish something... and it may be very meaningful and it may be very intelligent and it may be revolutionary, but if no one sees it besides a few academics, then what's the point?

For this participant, her love/hate relationship with academia acted as a push-pull factor that prevented her from making a decision for a long time. It was a combination of factors, including academic, supervision, and financial, which ultimately led to her decision to withdraw from her doctoral program. Reflecting on the structure of academia, she came to the conclusion that "...ultimately, academia is really freeing, but at the same time it seems kind of restrictive as well."

\section{Individual Characteristics}

Participants highlighted the role of individual characteristics in persistence and the need to "keep on carrying on". While some did not consider this to be a challenge for them personally, for others it was a significant struggle.

It comes down to individual willpower in graduate school and the character of who you are as a person. And I hate when people tell me this but it's kind of the truth. They're like, 'Just buckle down and get it done.' It comes down to your work ethic...sometimes it's very hard to organize yourself because it's independent work...you're working for yourself. I have huge troubles motivating myself, punching in the hours that I need.

A sense of commitment or obligation to the people or the topic they were studying played a significant role for some participants.

...you develop a bond with the people you are studying...they've kind of co-produced it with you and you have an obligation to see it to the end...

A fear of failure, or of letting others down, was identified by a significant number of participants as having a positive effect on persistence. This was especially true for those who had previously left a doctoral program without finishing.

...Well, no one likes to fail, and having not succeeded twice I simply decided that come hell or high water I was going to get it done...It's a matter of sticking to a task until it's completed. I didn't want to be a three-time loser... 
Many of the participants credited personal interest or commitment as a key factor that influenced their decision to continue on in their doctoral program.

It really was a deep-rooted personal goal. I had a lot of psyche invested in this thing. So I just wasn't going to give up.

I just loved what I was studying and what I was doing. My interest in that sustained itself all the way through. I really loved doing it.

Previous research has found that intellectual curiosity or 'intrinsic interest' is the most important characteristic for making the transition to becoming an independent researcher and for success in a doctoral program (Lovitts, 2008). While this may be considered a factor external to the university, it may be shaped by the culture of the institution, department, or discipline. It is clear that an inherent passion for the topic or study is enough for students to persevere despite facing significant challenges.

Participants also noted the role of individual characteristics that may inhibit persistence or delay progress. Many spoke to the need to have a good work ethic.

I think a big impediment is trying to learn the maturity it takes to become a genuine scholar.

Procrastination was mentioned as a significant barrier to persistence, with many participants mentioning the challenge of motivating themselves to work independently and put in the time and effort necessary for success.

Participants also indicated the difficulties students often face in adjusting and learning to be independent researchers. This struggle was mentioned previously by students who considered leaving, and has been emphasized in the literature.

...when it comes to...following your own trail of ideas and sifting through all the literature, doing all that by yourself, that was a challenge for me. I don't think I quite knew how to be an independent learner.

For those students who were switching to a new discipline at the doctoral level - which was the case for several participants - this transition also proved particularly challenging.

\section{Support of Others}

The most frequently cited factor considered by participants to be an important factor in persistence was the level of support received from both those within the program, such as faculty and supervisors, and those outside, namely, family and loved ones. Several participants mentioned what they felt was a high level of departmental, faculty, and supervisory support as an important factor that influenced their decision to persist.

[support from faculty] helped reel things back in. I think it was more a case of needing to feel assured that the work I was doing was valuable and... that people were paying attention.

Participants felt that having a supportive supervisor was essential to doctoral student persistence, which is consistent with previous research that has emphasized the role of the advisor in student success and satisfaction with the doctoral experience (Barnes, 2010; Golde, 1998; Zhao et al., 2007).

I have a really great supervisor, and he has been really the sort of, in terms of the [university] community, the single source of motivation, encouragement and support that has kept me going as a graduate student really. 
Participants did also mention the possible implications of a 'failed' relationship with one's supervisor, which may tarnish the students' experience and, ultimately, determine whether or not they persist to graduation. A few extreme cases of strained supervisor/student relationships, which led to participants' feeling inadequate and ashamed, were shared.

I would speak to people who had the same supervisor as myself, and they told me very similar stories and really, quite frankly, they were relationships of abuse.

It was very difficult and he had very strange standards for the level of work that he expected...I still feel like his expectations were very unreasonable. I felt like he was pushing me beyond my limit, in terms of the work that he wanted me to do.

Responses from participants did raise an important point for consideration: what constitutes 'reasonable' expectations from a supervisor, particularly with respect to program requirements, is sometimes unclear to students. Research has shown that "devoting extensive time and energy to their academics and not knowing if they are progressing appropriately" causes "undue stress" on students (Witkowsky, 2010), which calls for the need to make degree requirements clear and to encourage open communication between supervisors and students. Frequently, participants in this study pointed to the need for increased levels of supervisory and faculty support and the desire to see a mediator role created to give students a safe space to go to when problems arise.

[We need] more opportunities to talk about your experiences with your supervisors, because then maybe that's a way that the administration can become aware of continued and ongoing problems with certain specific people... those conversations need to be had.

Participants pointed to the management structure of academia as being partly responsible for the demands being placed on faculty to gain students.

I think that if there was a culture of collaboration, more so than a hierarchy or more so than thinking about 'I'm the supervisor, you're the student' kind of thing...I think students would be happier and I think more would finish...

Despite acknowledging the pivotal role of the support of others, participants frequently spoke to the sense of isolation and loneliness they felt, particularly at the independent phase of their program. The importance of peers, emphasized in the literature as an important component of socialization (Hildebrandt, 2011; Lovitts, 2001; Sweitzer, 2009) and social support (Jairam \& Kahl, 2012), was rarely mentioned by participants, which is indicative of an absence of social networking opportunities for Arts doctoral students at the institution under study.

I wish there was more culture on campus...The community is, in some ways, fragmented. I think it could be helpful for graduate students if that community seemed more solid...I would like to see more of a sense of solidarity...

While this finding is not surprising, given that the social sciences and humanities disciplines are characterized, to a large extent, by independent work as opposed to the collaborative approach that is typical of research in the sciences, it is interesting in light of the current literature on social and academic integration.

Social supports were most frequently cited when participants were asked to identify the types of support services and programs they would like to see offered specifically for graduate students, and this was seen to be an especially important resource for students who came from other provinces and countries.

Any university has to understand that people that come to them to study don't have this huge social network. I think people brought up in that milieu sort of take it for granted, but for people from away it's a huge challenge and it can make a very big difference in the outcomes. You kind of have to create the opportunities for people to meet socially. 
Participants were of the opinion that the university and the academic community as a whole needs to look beyond the academy in terms of helping graduate students to transition out of school into the workforce.

...having a strong forward-looking view on academia would be really great: helping students to see where they could end up when they finish their degrees.

A few participants also emphasized the important role of the department in providing graduate students with a supportive and collegial environment; "Having a cohesive department as a whole or a group of graduate students work together."

\section{Discussion}

Overall findings from this research suggest a low level of awareness and knowledge about support services available to doctoral students at the institution under study. Participants implied that they are generally not very familiar with the array of supports available to them, nor are they very clear on the role of specific administrative and academic units with regards to providing these supports. A disconnect between the quantity and quality of services available and doctoral student awareness of, use of, and satisfaction with these services is evident. Furthermore, the frequency with which student-initiated persistence strategies were mentioned, a finding that is substantiated by previous research (Franco-Zamudio, 2009), points to the need for structural change at the administrative level.

Tinto (2011) recently posited that graduate student attrition may be less easily amenable to institutional support than undergraduate attrition. While further research is needed to explore the role of institutional support on graduate student success and persistence, it may be possible that a lack of awareness and knowledge of what support is available is more responsible for this apparent disconnect between support service and persistence than is an inadequate level or quality of services.

Financial support was found to be both a motivator for, as well as a barrier to, persistence. The role of financial support in graduate student retention and attrition has been established (Strayhorn, 2010). Participants specifically cited employment as a barrier to persistence and a cause of lengthy times to completion. To date, research on the effects of employment on doctoral degree progress and completion has produced mixed findings (Boulder, 2010; Gittings, 2010).

Previous research has explored the effect of perceptions on person-environment fit on graduate student persistence and found that identification with academia and the integration of social group identities with an academic identity enhanced students' perceptions of fit in academia and was associated with increased levels of commitment to persistence (Franco-Zamudio, 2009). Findings from this study revealed that participants recognized the potential mismatches between their personal and career goals and the structure of academia, and, for some, a perceived ill fit between personal identity and the academic lifestyle was seen as a significant barrier or 'risk factor' to persistence.

The belief that only a select few students have what it takes to make it through graduate school has been referred to in the literature as the 'survival of the fittest' mentality (Bowen \& Rudenstine, 1992; Lovitts, 2001). Gardner (2005) questions whether the ambiguity and lack of clarity doctoral students experience is somewhat intentional, as scholars see this as part of preparing the next generation for the uncertainty they can expect in the academic profession. Bieber and Worley (2006) note that the socialization process that occurs in graduate school is in fact incomplete, and for socialization to be effective, student views and constructs of faculty life must be considered and compared to the schemas held by faculty, as a misalignment may impede communication and prohibit positive socialization for the student. 
Participants also noted the role of individual characteristics that may positively influence persistence, such as having an intrinsic interest in their topic or study, as well as being motivated and proactive. This independent mindset is considered to be particularly salient at the candidacy or final stage of doctoral studies (Tinto, 1993; Weidman et al., 2001). Other participants highlighted personal struggles to overcome problems such as procrastination and learning to become an independent researcher.

Participants frequently cited the support of others, those both internal and external to the university, as having a positive influence on their persistence through doctoral studies. The positive influence of internal and external sources of support such and family and peers has been demonstrated in previous research (Boulder, 2010; Jairam \& Kahl, 2012; Williams-Tolliver, 2010). While participants most frequently cited the need for further social supports, little mention was given to the need to boost efforts aimed at increasing academic integration.

In a recent study that examined persistence factors associated with the successful completion of a doctoral degree in the field of education, students identified factors associated with both social and academic integration (Spaulding \& Rockinson-Szapkiw, 2012); likewise, Gilardi and Guglielmetti (2011) found that the most important variables in the retention of non-traditional students are an increased use of academic support services and higher levels of perceived social integration. Earlier work by Tinto (1993), and later Lovitts (2001), point to an increased emphasis on academic integration at the doctoral level.

\section{Limitations}

As in any study, it was anticipated that there would be limitations that may restrict data collection and/or the analysis and interpretation of the findings. As this study was conducted at only one institution, the findings are not generalizable to the larger graduate student population. The purpose of this study was to explore and describe the experiences of individual students in an individual setting. While every effort was made to ensure that each department and program in the Faculty of Arts was represented, due to the voluntary nature of participation, this was not always possible.

Only six departments out of a possible sixteen were represented through doctoral interview participants: anthropology, archaeology, English, folklore, history, and sociology. Although composing $10 \%$ of the total study population, there was little representation from the department of English Language and Literature, despite extensive recruitment efforts. There were also no interview participants from western Canada, although these provinces comprised approximately $7 \%$ of the total study population. Unfortunately, due to circumstances beyond the control of the researcher, complete demographic and program information for the total study population was not available; some data for this group is incomplete or missing. This was partly the result of the changing nature of this information as it is generated electronically by the Office of the Registrar; students' status may have changed over the period of time from which the survey was distributed and when this data was compiled for analysis.

Findings are limited by the researcher's own interpretation of observations and the information provided by students, departments, and the institution. Analysis of the data was limited to individual interpretation and may not be an actual representation of students' experiences, though an attempt to counter this effect was made through member checks, peer debriefing, and triangulation, as discussed above. The exclusion of faculty and staff limited the scope of this study, as the absence of these individual's perspectives give an unbalanced account of the doctoral student experience at this institution. Differences in departmental representation may have affected the findings that emerged from this research, and major themes may have thus been overlooked. 


\section{Conclusion and Recommendations}

The purpose of this study was to explore the various forms of supports available to assist doctoral students and to determine the effects, if any, of these services on persistence. Participant's accounts have revealed considerable insight into the role of support services, as well as identified a number of factors that may work to either deter or motivate persistence. Five predominant themes emerged with regards to doctoral student persistence: (1) the unclear role of institutional support; (2) financial considerations; (3) the culture and structure of academia; (4) individual characteristics; and (5) support of others.

Findings from this study indicate that doctoral students' perceptions of the role of support services in persistence is shrouded in a veil of ambiguity, pointing to the need for transparency among university and graduate program administrators, which may be achieved by making their roles explicitly clear to the students they serve, and by promoting and raising awareness of the services they offer. Study participants implied that they are not very familiar with programs and services offered, nor are they very clear on the role of each of the specific divisions that offer these supports. It is uncertain whether these perceptions are typical of doctoral students in general, specific to certain disciplines or this institution in particular, or common across various institutional types. Further research is needed.

It is recommended that universities as a whole, and specifically academic and administrative units, make known to doctoral students the academic and social supports they have available. University websites should clearly list and outline services and programs for graduate students, and provide links for them to access external resources. These efforts to promote and raise awareness of support services are a critical piece in building a sense of community and belonging for doctoral students.

A range of institutional factors may act as barriers to, and/or positive motivators for, doctoral student persistence. Doctoral students' perceptions on the role of support services revealed that a number of factors exhibit a push-pull effect on the persistence decision-making process: financial considerations, the culture and structure of academia, individual characteristics, and the support of others. The finding that a number of factors have been identified as both challenges and/or supports emphasizes the importance of maintaining a balance between the two in order for development to occur.

Research findings in this study are consistent with the existing literature in implying that extended times to completion is an unfortunate consequence of students having to balance work and study priorities due to financial strain. Future research would do well to examine more closely the effects of on and off campus employment, such as holding a part-time research or teaching position, or a full-time professional job, on graduate student socialization, level of engagement and involvement, and persistence. It is recommended that information about fellowships and other forms of funding should be included with offers of admission, and new incoming students should be made aware of the various scholarships and awards for which they may be eligible to apply.

The culture of the institution and a lack of 'perceived' support was seen as a barrier to persistence. Students' perception of a poor fit between their own expectations and those of the institution, doctoral studies, graduate school in general or their department has been found to be a cause of attrition in previous research. This points to the importance of promoting and raising awareness of support services.

It is advised that university and graduate program administrators make graduate program expectations and requirements clear early on to prospective students. Opportunities for new students to be mentored by senior doctoral students and/or faculty members should be explored. Participants in this study also mentioned the need for a 'mediator'- a neutral 'go-to' person that students can 
turn to for advice. Previous research supports this need (Acker \& Haque, 2010; McAlpine, Paulson, Gonsalves, \& Jazvek-Martek, 2012).

Participants cited a number of individual characteristics or personal attributes that may have either a positive or negative effect on persistence. Motivation, commitment, and interest were mentioned as traits that are encouraging factors, while procrastination as well as challenges with writing and conducting independent research were seen as deterrents to persistence. Future research should examine the effects of personal methods of coping with the rigors of doctoral study in more depth, especially in contexts where there is a lack of institutional support services. It is also recommended that academic research and writing groups, seminars, and workshops be made a formalized component of doctoral programs, which has been suggested by previous research (Gittings, 2010).

Participants indicated that the most important factor influencing persistence is the support of others - those both inside the university, primarily faculty and supervisors, and those outside, such as family and friends. Responses highlighted in particular the need for further social support; academic peers were rarely mentioned as a source of support by participants, pointing to the need for opportunities to connect doctoral students on campus. Further research should explore the role of different types of both internal and external supports on the graduate student experience in more depth.

It has been made clear that having a healthy, mutually respective relationship with one's supervisor is vital to doctoral students' persistence and academic success. Yet, participants also noted that the role of the supervisor as well as what constitutes 'reasonable' expectations from a department or with respect to program requirements is sometimes unclear. Participants mentioned the possible ill effects of a poor student-supervisor relationship, and this corroborates existing literature.

Graduate program administrators should encourage incoming doctoral students to actively participate in choosing their supervisor; where this is not possible, informed decisions should be made with regards to this selection process and the relationship monitored so that potential problems can be detected before they become damaging to the students' progress, and re-assignments made. It would be beneficial for new faculty members and those new to supervising graduate students participate in supervisor training; workshops and seminars could be provided on a regular basis through academic units and/or schools of graduate studies.

Finally, future research should work to provide further insight into the role of push-pull factors both those identified here as well as those that are absent - on working to achieve a balance of challenge and support to aid in doctoral student development and persistence.

\section{References}

Acker, S., \& Haque, E. (2010). Doctoral students and a future in academe? In L. McAlpine \& G. Akerlind (Eds.), Becoming an academic: International Perspectives (pp.96-124). Basingstoke, NY: Palgrave Macmillan.

Astin, A.W. (1984). Student involvement: A developmental theory for higher education. Journal of College Student Personnel, 25(4), 297-308.

Bair, C. R., Haworth, J. G., \& Sandfort, M. (2004). Doctoral student learning and development: A shared responsibility. NASPA Journal, 41(3), 709-727.

Barnes, B. (2010). The nature of exemplary doctoral advisors' expectations and the ways they may influence doctoral persistence. Journal of College Student Retention, 11(3), 323-343.

Bean, J. P. (1980). Dropouts and turnover: The synthesis and test of a causal model of student attrition. Research in Higher Education, 12(2), 155-187. 
Bieber, J. P., \& Worley, L. K. (2006). Conceptualizing the academic life: Graduate students' perspectives. Journal of Higher Education, 77(6), 1009-1035.

Bogdan, R. C., \& Biklen, S. K. (2003). Qualitative research for education: An introduction to theory and methods (5th ed.). Boston: Allyn and Bacon.

Boulder, J. (2010). A study of doctoral students' perceptions of the doctoral support and services offered by their academic institution. (Unpublished Doctoral Dissertation). Mississippi State University, Starkville, MS.

Bowen, W. G., \& Rudenstine, N. L. (1992). In pursuit of the PhD. Princeton, NJ: Princeton University Press.

Brandes, L. C. O. (2006). Graduate student centers: Building community and involving students. New Directions for Student Services, 115, 85-99.

Cabrera, A. F., Castaneda, M. B., Nora, A., \& Hengstler, D. (1992). The convergence between two theories of college persistence. Journal of Higher Education, 63(2), 143-164.

Canadian Association for Graduate Studies. (2012). 40 Statistical Report 2000-2009. Ottawa, ON: Author.

Canadian Association of University Teachers. (2011). CAUT Almanac of Post-Secondary Education in Canada, 2011-2012. Ottawa, ON: Author.

Creswell, J. W. (2009). Research design: Qualitative, quantitative, and mixed methods approaches. Los Angeles, London, New Delhi, \& Singapore: SAGE.

Creswell, J. W., \& Plano Clark, V. L. (2011). Designing and conducting mixed methods research (2nd ed.). Thousand Oaks, CA: SAGE Publications.

Elgar, F. J. (1998). Broadening the focus of the office of student affairs and services for graduate students. St. John's, NL: Graduate Students' Union.

Elgar, F. J. (2003). Ph.D. degree completion in Canadian universities: Final report. Halifax, NS: Graduate Student's Association of Canada.

Ethington, C. A., \& Smart, J. C. (1986). Persistence to graduate education. Research in Higher Education, 24(3), 287-303.

Franco-Zamudio, J. L. (2009). Graduate student persistence: The effect of perceptions of personenvironment fit. (Unpublished Doctoral Dissertation). University of California, Santa Cruz, CA.

Gardner, S. K. (2005). "If it were this easy, everyone would have a Ph.D." Doctoral student success: Socialization and disciplinary perspectives. (Unpublished doctoral dissertation). Washington State University, Pullman, WA.

Gardner, S. K. (2009a). Conceptualizing success in doctoral education: Perspectives of faculty in seven disciplines. The Review of Higher Education, 32(3), 383-406.

Gardner, S. K. (2009b). The development of doctoral students: Phases of challenge and Support. ASHE Report, 34(6), 1-126.

Gardner, S. K. (2010). Contrasting the socialization experiences of doctoral students in high- and lowcompleting departments: A qualitative analysis of disciplinary contexts at one institution. Journal of Higher Education, 81(1), 61-81.

Gardner, S. K., \& Barnes, B. J. (2007). Graduate student involvement: Socialization for the professional role. Journal of College Student Development, 48(4), 369-387.

Gilardi, S., \& Guglielmetti, C. (2011). University life of non-traditional students: Engagement styles and impact on attrition. The Journal of Higher Education, 82(1), 33-53.

Gittings, G. A. (2010). The effect of student attributes and program characteristics on doctoral degree completion. (Unpublished Doctoral Dissertation). University of Louisville, Louisville, KY and Western Kentucky University, Bowling Green, KY. 
Glaser, B., \& Strauss, A. (1967). The discovery of grounded theory. Chicago: Aldine.

Golde, C. M. (1998). Beginning graduate school: Explaining first-year doctoral attrition. In M. S. Anderson (Ed.), The experience of being in graduate school: An exploration (pp. 55-64). San Francisco: Jossey-Bass.

Golde, C. M. (2005). The role of the department and discipline in doctoral student attrition: Lessons from four departments. The Journal of Higher Education, 76, 669-700.

Greene, M. (2013). Transitioning into, through and out of graduate school: A theoretical model. Canadian Journal of Career Development, 12(1), 49-57.

Greene, M. (2014). The hardest part is through: Support services and graduate student persistence in the social sciences and humanities disciplines. (Unpublished doctoral dissertation). Memorial University of Newfoundland, St. John's, NL.

Hildebrandt, D. (2011). Perceived impact of social network sites on online doctoral students' sense of belonging. (Unpublished doctoral dissertation). Walden University, Minneapolis, MN.

Holaday, B., Weaver, K. A., \& Nilson, L. B. (2007). Revisioning graduate professional-development programs. College Teaching, 55(3), 99-103.

Jairam, D., \& Kahl, D. (2012). Navigating the doctoral experience: The role of social support in successful degree completion. International Journal of Doctoral Studies, 7, 311-329. Retrieved from http://ijds.org/Volume7/IJDSv7p311-329Jairam0369.pdf

Lovitts, B. E. (2001). Leaving the ivory tower: The causes and consequences of departure from doctoral study. Lanham, MA: Rowman \& Littlefield Publishers.

Lovitts, B. E. (2008). The transition to independent research: Who makes it, who doesn't, and why. The Journal of Higher Education, 79(3), 296-325.

Luttrell, W. (2010). (Ed). Qualitative educational research: Readings in reflexive methodology and transformative practice. New York; London: Routledge.

McAlpine, L., Paulson, J., Gonsalves, A., \& Jazvac-Martek, M. (2012). 'Untold' doctoral stories: Can we move beyond cultural narratives of neglect? Higher Education Research \& Development, 31(4), 511523.

Mills, E. J. J. (2006). Graduate students: Are they our forgotten residents? Journal of College and University Student Housing, 34(1), 11-13.

Mullen, A. L., Goyette, K. A., \& Soares, J. A. (2003). Who goes to graduate school? Social and academic correlates of educational continuation after college. Sociology of Education, 76(2), 143-169.

Oswalt, S. B., \& Riddock, C. C. (2007). What to do about being overwhelmed: Graduate students, stress, and university services. The College Student Affairs Journal, 27(1), 24-44.

Pascarella, E. T., \& Terenzini, P. T. (2005). How college affects students (Vol.2). San Francisco: JosseyBass.

Polson, C. J. (2003). Adult graduate students challenge institutions to change. New Directions for Student Services, 102, 59-68.

Poock, M. C. (2004). Graduate student orientation practices: Results from a national survey. NASPA Journal, 41(3), 470-486.

Sanford, N. (1966). Self and society: Social change and individual development. New York: Atherton Press.

Seidman, I. (2006). Interviewing as qualitative research: A guide for researchers in education and the social sciences. New York: Teachers College Press. 
Spaulding, L. S., \& Rockinson-Szapkiw, A. J. (2012). Hearing their voices: Factors doctoral candidates attribute to their persistence. International Journal of Doctoral Studies, 7, 199-219. Retrieved from http://ijds.org/Volume7/IJDSv7p199-219Spaulding334.pdf

Strange, C. C. (2010). Theoretical foundations of student success. In D. H. Cox \& C. C. Strange, Achieving student success: Effective student services in Canadian higher education (pp.18-32). Montreal; Kingston; London; Ithaca: McGill-Queen's University Press.

Strayhorn, T. L. (2010). Money matters: The influence of financial factors on graduate student persistence. Journal of Student Financial Aid, 40(3), 4-25.

Sweitzer, V. B. (2009). Towards a theory of doctoral student professional identity development: A developmental networks approach. The Journal of Higher Education, 80(1), 1-33.

Tinto, V. (1975). Dropout from higher education: A theoretical synthesis of recent research. Review of Educational Research, 45(1), 89-125.

Tinto, V. (1993). Leaving college: Rethinking the causes and cures of student attrition (2nd ed). Chicago: The University of Chicago Press.

Tinto, V. (2011, May 9). Interview by D. Kirby [Digital recording]. Distance Education, Learning and Teaching Support (DELTS), Memorial University. Retrieved from http://www.delts.mun.ca/portal/index.php?SAID $=187 \&$ Cat $=\% 22$ Teaching_and Technology $\% 22$

Tinto, V. (2012). Completing college: Rethinking institutional action. [Kindle e-book]. Chicago: The University of Chicago Press. ASIN: B007HA3C6U

Walker, G. E., Golde, C. M., Jones, L., Conklin Bueschel, A., \& Hutchings, P. (2008). The formation of scholars: Rethinking doctoral education for the twenty-first century. San Francisco: Jossey-Bass.

Weidman, J. C., Twale, D. J., \& Stein, E. L. (2001). Socialization of graduate and professional students in higher education: A perilous passage? ASHE-ERIC Higher Education Report, 28(3), San Francisco, CA: Josssey-Bass.

White, J., \& Nonnamaker, J. (2008). Belonging and mattering: How science doctoral students experience community. NASPA Journal, 45(3), 350-372.

Williams-Tolliver, S. D. (2010). Understanding the experiences of women, graduate student stress, and lack of marital/social support: A mixed method inquiry. (Unpublished Doctoral Dissertation). Capella University, Minneapolis, MN.

Witkowsky, P. A. (2010). Voices of well doctoral students: A case study exploration into the possibilities of academic and personal success. (Unpublished Doctoral Dissertation). University of Northern Colorado, Greeley, CO.

Zhao, C-M., Golde, C. M., \& McCormick, A. C. (2007). More than a signature: How advisor choice and advisor behaviour affect doctoral student satisfaction. Journal of Further and Higher Education, 31, 263-281.

\section{Biography}

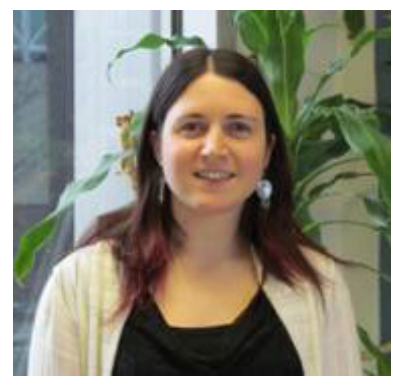

Melanie J. Greene, Ph.D., teaches in the Faculties of Arts, Business Administration, and Education at Memorial University of Newfoundland. She earned her doctorate in Education from Memorial. She also holds a Master of Arts degree from McMaster University and a Bachelor of Arts (Honours) from Memorial, both in sociology. Her research interests include the sociology of higher education, graduate education, socialization and professional development processes, and the role of support services in post-secondary student retention and success. She writes and publishes widely on a broad range of topics. 